\title{
Education and Economic Growth in Vietnam
}

\author{
Thi Thanh Binh Dao* Ngoc Hieu Trinh \\ Hanoi University, Faculty of Management and Tourism, Km 9 Nguyen Trai, Thanh Xuan District, Hanoi
}

\begin{abstract}
The relationship between education and economic growth has always been considered a fundamental concern of many economists as well as governments. This research provides empirical evidence of the education true effects are not well understood, especially in Vietnam. This research provides empirical evidence of the influences of education in Vietnam's economy, more specifically on Vietnam's productivity, from the period 2000 to 2015 . The paper find that the final findings are supportive to the hypothesis made: education is critical factor of economic enhancement. More specifically, primary and secondary schooling levels better the productivity of the economy estimated by the Total Factor Productivity and the GDP growth.
\end{abstract}

Keywords: GPD growth, social return, TFP

DOI: $10.7176 / \mathrm{JEP} / 11-6-02$

Publication date: February $29^{\text {th }} 2020$

\section{Introduction}

It is a common sense to believe that education is beneficial to individuals. In a research in 2013, OCED ${ }^{1}$ researchers had stated that the final goals of education are to bring moral satisfaction to individuals and improve the society conditions. Not only can schooling enhance workers' positions in the labor market, but it also can better their overall health, and reduce crime rate. Another aspect of life that education can improve is human's life span which reflects human's health condition and other ethical issues. Tests' results had proved that people's longevity is directly linked with education: a 30-year-old educated man is expect to living 17 years longer than less educated one. Schooling can additionally increase the social activities participation rate. OCED report showed that adults with higher levels of knowledge tend to be more engaged in civic activities such as voting, volunteering. One last example of how education can affect humanity is that ones who have higher degrees feel more fulfilled in life and have higher income than others (OCED, 2013).

Citizens are not the only beneficial one, education can also enhance the whole countries' economic performance. According to a paper done by World Bank, schooling is the basis for financial growth and reduction in poverty and it provide the labor market with high quality workers and stimulate new invention (Patrinos \& Montenegro, 2013). Moreover, education helps employees increase their human capital by enable them to new skill sets and knowledge; thus, improve their productivity. Hence, Saxton (2000) called education a "public good" of every society . Regarding this issues, many famous economists have issued their paper to measure education's impact, for example: Barro (2002) with "Education as a Determinant of Economic Growth", Moretti (2004) with "Estimating the social return to higher education: evidence from longitudinal and repeated cross-sectional data".

Realizing the fundamental role of education, ever since 1945, Vietnamese government have put generalizing schooling for all in one of their main tasks $\left(\mathrm{MOET}^{2}, 2014\right)$. After many changes since feudal time to the current date, especially after the reformation in 1986, the Vietnamese education system takes structure as Early state (Kindergarten, nursery), General education (Primary school (5 years), Secondary school (4 years), High school (3 years)) and Higher Education (College (3 years), University (4 to 6 years)).

Moreover, authorities have been putting effort into boosting the educational system. The period from 2000 to 2012 witnessed a quite amazing growth. Since 2000, all most all children from the age of 6 have had access to the primary education, and in some region of Vietnam, even secondary level had been generalized (MOET, 2014). The quality of schooling system has also been gradually enhanced and meet the requirement from the labor market. In additional, state budget portion for educational reasons increased constantly since 2001 .

From the above information, it can be seen that attention on schooling has been raised in Vietnam. Nevertheless, researches regarding the economic return from education in Vietnam is still quite rare. Recognizing the vital nature of the problem, with intention to clarify and to decide whether the investment made for education been advantageous for the whole country, the research question is whether or not schooling deliver any positive outcome in Vietnam.

Given the background and the research question, the main goal of this paper is to briefly analyze some former theories, and then use them as the base to introduce a suitable model for estimating the effect of education on the economic growth. From that model, data will be collected and processed using reasonable method and program. This paper contains data of several fields of study relating to Vietnamese economy from the year 2000 to 2015 . The paper find that the final findings are supportive to the hypothesis made: education is critical factor of economic

\footnotetext{
${ }^{1}$ Organization for Economic Cooperation and Development

${ }^{2}$ Ministry of Education and Training
} 
enhancement. More specifically, primary and secondary schooling levels better the productivity of the economy estimated by the Total Factor Productivity and the GDP growth. With those results, this research hopefully can illustrate and bring some insights of the relationship between education and the economy of Vietnam. It can help both citizens and authorities see the urgent of the topic, therefore, take efficient actions to enhance the strength of both individual and the whole nation.

This paper is focus to quantify and briefly analyze the financial effect of investing in education and its outcome in Vietnam from 2000 to 2015. The research contains three main sections, first is the Literature review, some of the previous findings and its result will be mentioned for an overall status the problem. After that, some procedures of calculation such as collecting data and utilizing econometric models, are used to evaluate the return on education. Consequently, the last part is used to examine and interpret the outcome. The literature review is divided into four main parts to clarify some former works of economists. The first part is reviewing economic growth. The next section is dedicated to determining the relationship between economic development and education based on the mentioned theories. Afterwards, the actual return to education is specified and lastly, the ending parts was written to disclose some of the paper from Vietnam and other nations.

\section{Literature Review}

\subsection{Economic growth}

A country's financial development is considered to be the most powerful tools to push living standard forward and hold back poverty (Development, 2008). Hence, growth is a crucial area for all economist and it is fundamental to understand how societies and economies varies.

According to classical economists, main factors affecting one country's prosperity are the inputs, for examples land, labor and the overall structure of the society, economy and politic system. In order to figure out how to maintain a sustainable growth, Adam Smith had come up with one of the most basic and typical theory of classical economy, his theory can be expressed that the economy's output Y is a function of K-capital, L-labor, Nland. In his view, economic advances are driven by the increase in population and capital, the existence of labor specialization and the equality to trade among all firms in the market. Smith also stressed on the importance of the "invisible hand": the force which merges personal's interest with the whole nation's welfare. The famous economist considered the selfishness of any individual is a normal nature and there is no doubt that one will put himself/herself above all and therefore, citizens usually spend little to no effort to better the society; however, by promoting their own condition, people has added values to the whole economy - hence, led by an "invisible hand" to contribute to the overall growth (Ucak, 2015).

Robert Solow and Trevor Swan had brought about their own version of growth model - so called the "Neoclassical" growth model. With the assumption of constant returns to scale (countries have no gains from specialization), they constructed the function explaining the long-run development of financial status using labor and capital as inputs (Sardadvar, 2011). Though in the original version, technical progress (technology innovation) only studied briefly, however, on Solow's latter paper he conducted the test that leads to the conclusion that output is a function of capital, labor and technology progress. From this function, it can be interpreted that technological progress is a labor-augmenting factor - which means it help better labor variable. In addition, pursuance with the model, one of the two main ingredients (capital and labor) must be available or else the output will equal to zero; and any desired output can be produce by efficient amount of capital and labor. Another consequence from the model is that marginal product trend is usually positive and diminishing (Sardadvar, 2011) - benefits from extra unit of output decreases as the level of inputs increase (Mankiw, 2011).

Nevertheless, in the last few decades, economists' interest was drawn to the relationship between technological progress and long run economic growth; hence, based on "Neo-classical" theory, the "Endogenous Growth Theory" appeared (Sardadvar, 2011). After looking at three main models of this new wave of theory, Fontenele et al. (2015) conclude that there is a significant linkage between technical progress and the improvement of an economy. In additionally, economic policies are becoming more and more influential towards growth as well as government interventions and international trade (Sena \& Fontenele, 2000). However, despite being accurate for explaining the growth in one nation independently, the new model's is quite problematic and complex when it comes to estimate the influences between regions; thus, further empirical tests are needed (Sardadvar, 2011).

\subsection{Education and economic growth}

Regarding the issue of the relationship between education and economic growth, Geraint (2006) he looked at two main model of economic growth: the old model which is "Neo-classical" and its newer version - Endogenous Growth Theory. The central of the "Neo-classical" model was the diminishing effect, which implies that country can effortlessly catch-up with others while trying to take the lead can be quite difficult. With this view, the theory state that GDP growth rate is determined by the growth of technical progress; nevertheless, the technical development is considered to be an exogenous factor. The growth of technology differs between nations; however, thanks to the diminishing effect, poor countries tend to have a higher rate than developed countries. 
In "Neo-classical" model, economic growth rate and the technical progress are mutually dependent. In order to enhance a country's economic status, one must rely on research and development, which implies the importance of education and "human capital". Human capital is the skill set that workers gained by practical and theoretical training which help them to become more productive. This test is conducted by using the average marks of 6 subjects from 90 countries during the period of 1980 to 2000. Afterwards, all of the required data collected are plotted on a scatter plot against economic growth to examine their relationship. The result was that the test scores - representing quality of education and growth had a positive relationship and the explanatory power of education quality was proven. One dispute might arise from the hypothesis of this study is that since a country relied on research and development mostly, providing education for everyone is not the as effective as providing higher education for people at the end of education ladder/people in research and development area. However, reflecting on Castello and Doménech (2002) using education Gini coefficient, inequalities in distribution of schooling will dampen the growth of an economy, approximately $42 \%$ of the fluctuation of international growth rate can be explained by education.

With the focus to describe education as a determinant of economic growth, Barro (2002) had also looked at neoclassical and its newer version. He stated that human capital is the globe has the ability to grow continuously even when there is diminishing effect. Barro's empirical study utilized the average GDP growth rate (per capita) of around 100 countries from 1965 to 1995 and then related them to the educational data. In his view, the most reliable method to determine schooling figure is the average attainment period of 25 -year-old men and older. The main hypothesis of Barro's research is that nation with better human capital level will have better physical capital creation process. Consequently, they may have higher economic growth, mostly by being able to absorb new production techniques.

The initial finding of Barro's work is that secondary and higher participation data had positive and significant effect: an extra year spent is school can raises the national annual economic growth by $0.44 \%$. Nonetheless, female participation data was found to be insignificant, which was caused by some countries' discriminatory regulations. Though playing a foundation role, for both gender, primary attendant rate was not significant. This provided proof for the beginning hypothesis: better education provides better technology comprehension and imitation - what can only be done with higher level of education.

All in all, it is clear that quantity and quality of education affected greatly the financial improvement of a country. Hence, to improve the economy and citizens' prosperity, governments should take careful actions to promote the schooling systems.

\subsection{Return to Education}

From the first part, the importance and the significant role of education in economic growth had been touched. To clarify the cause of this connection, the actual return from investing in the schooling system.

\section{Social Return}

Mingat and Tan (1996) have begun the measure of social return. They divided the investment in schooling system into 2 groups: investment to maintain and investment to expand - which is more important. As consequences to assess the return, cost and benefit should be considered first. Costs to individuals were defined by the authors as the out-of-pocket (including tuition) costs and the opportunity cost. To the society, cost included tax-financed allowances for education. The combination of those expenses made up the full cost of education. In contrast, being educated will help people to increase their productivity and enjoy private non-market effects such as better health status, recreation activities. Investing in training can create an effect called "spillover": the knowledge of one worker escalates the capacity of other co-workers. In addition, it can also widen the technological condition and bring about community non-market effects such as less contagious diseases, reduction in crime rate (Mingat \& Tan, 1996).

After defining the total cost and benefit, Mingat and Tan (1996) used the assumption that the influences will appears in the long-term economic performance to calculate the outcome of education. They used the data of longrun economic growth and the enrolment ratio of 113 countries to apply the median regression method. 113 regions in this test were separated into three main groups: low-income, middle-income and high-income, and there were also three level of participation as well: primary, secondary and tertiary enrollment rate. The results afterwards was quite surprising, poor countries profited the most from primary education, whilst middle-class and wealthy nations enjoyed growth from high secondary and higher education enrollment ratio.

With the above finding in mind, the authors tried to calculate the full return of education investing by using full discounting method of the mentioned benefit and cost stream over a period of 25 years. In lower-income countries, since their production is quite simple, training at primary level can provide them skills to complete most jobs. Hence, investing in those classes would be most profitable: one standard error change in regression coefficient could raise the rate of return by $32 \%$ to $61 \%$. For middle income group, putting secondary education in priority will help advance the development quicker: $37 \%$ to $66 \%$ of increase can be distribute by one standard error change. Lastly, although at a much slower pace, only focusing on higher education can aid the evolution of 
higher income areas (Mingat \& Tan, 1996).

Disbursing capital to education will certainly bring back positive result to the whole society; nonetheless, the outcome differs between countries. At the same time, does this outcome vary from private return to individuals? To clarify this concern, Moretti (2004) in his study confirmed that it is possible for social return to education to exceed private return, thanks to the spillover effect (Moretti, 2004a).

Moretti (2004) used the sample of over 100,000 people aged 23 to 37 during the period of 1979-1994. He established the null hypothesis that all the return from college education will be distributed in term of wages and the face that other workers will benefit from college students' knowledge is considered to be the alternative hypothesis. There were two main problems arose: there might be unobservable city-specific and individual characteristics. To avoid them, Moretti used the system of longitudinal non-random data and instrumental variables. The conclusion was that there was a major positive relationship between individuals' income (including both college graduates and non-graduates) and the share of college alumni. This means that a rise is higher-educated employees leave an upward effect on both the productivity and monetary payment of less-educated workers - the spillover effect. Hence, the null hypothesis is rejected and the alternative hypothesis is somewhat proven. Illustrating spillover effect, the Moretti produced another article for The American Economic Review showing the effect in different industrial plant. After tests, it is proven that plants established in regions where the number of college graduates grew faster enjoyed larger development in productivity (Moretti, 2004b). Moreover, the differences in salaries of cites with high and low levels of human capital shared the same pattern. Interestingly, the importance of human capital was much more appreciated in low-tech plants and manufacturing plants gained most from being close both geographically and economically to high human capital plants.

Also concern over the social return of education but in another aspect, Moretti and his partner introduces a paper over the influences of schooling on the crime rate in 2004. Their final findings was the education was a fundamental factor for the reduction of imprisonment (Moretti \& Lochner, 2004). The method that education can leave effect on crime rate is by increasing citizens' earnings, and making the opportunities cost for being in prison higher. Being in school also help raise awareness of people, make them more patient and keep them away from breaking the law. By reducing the number of criminal, not only education can make the society safer, but it also saved the government a great amount of budget. $1 \%$ grow in high school completion rate could save the United States $\$ 1.4$ billion per year.

\section{Private Return}

Despite consisting also the non-market benefits, private return from education has long been measured by its contribution to individuals' income (Patrinos \& Montenegro, 2013). In the research paper prepared for the World Development Report (2013), Montenegro and Patrinos (2013) had compared this kind of return as the most important illustrator of productivity and inevitable stimulus for citizens. They also took into account the earnings of 545 households across 131 economies from 1970 to 2011 to determine the actual impact of education.

With the above set of number, identical to social return, first the total costs and benefits needed to be deliberated - a useful tools acknowledged in the essay was Becker and Chiswick semi-log earnings function. Their finding was that one additional year of schooling could help earning go up about $10.4 \%$ in average. The highest rate of return was from tertiary level of education at about $16.8 \%$, the second place was primary education. This indicated that well-trained workers are in scarce supply and the needs for them is increasing. Another result can be derived from the test was that lower income countries required the most primary graduates and the rate of return from these countries tended to be the highest.

In 2014, the same authors from World Bank issued another paper called "Comparable Estimates of Returns to Schooling Around the World" with compatible findings with those mentioned above. Nonetheless, the focus of the 2014 report is to distinguish the return between countries and between genders. The outcome for female workers was $11.7 \%$, much higher than male workers' 9.6\% (Patrinos \& Montenegro, 2014). This is true not only for return on additional year of schooling: women gained much more for each level of education (namely primary, secondary and tertiary) comparing to men. Regarding the differences between countries, the top five highest returns all belonged to African nations while the compensation for another year of schooling for Middle East/North Africa area was the lowest.

Another trend that was noticed in both of the paper above was the downward movement in the return to educations, especially since the 1980s (Patrinos \& Montenegro, 2013). The major cause to this was the unprecedented acceleration in number of schools around the globe. Moreover, the outcome from further schooling decreased and the overall price increased as the average level of education improved (Patrinos \& Montenegro, 2014).

\subsection{Education and Economic Growth}

In Vietnam, the concern over education's effect on the economy had also been considered as an important issue. Recently, Ngo (2015) had issued an update over the relationship between economic growth and the investment in education of Vietnam from 2000 to 2012. He stressed again on the importance of education: in order to gain a 
successful economy and a civilized society, the labor force must be highly developed in both physically and intellectually. Furthermore, the formation of skill sets and enhancement of productivity must be transmitted through education and training. Examining the data over government's investment to education, the author recognized that this amount had increased steadily from 2000 to 2012, with the average rate of $121.18 \%$ per year. On the other hand, during this period the overall economic development is around $118 \%$, so the question of connection between these numbers is raised.

It showed that there was a direct and positive connection between the two variables: GDP and Budget for education. In addition, an additional equation where educational budget was the dependent variable also indicated the similar answer. In conclusion, there was a relationship between the financial growth and the investment in schooling system, but this relationship in Vietnam case was still weak and insufficient (Ngo, 2015). To better the situation, the author suggested that there should be innovations in the management of educational funds and clearer plans should be issued by the government for enhancement.

The relationship between investment in education and economic had also been examined at country level. Saxton (2000) found that increase the level of human capital raised the level of income for individuals up to $10 \%$ in 1993 and this trend would continue to grow as the demand from firms continue to develop. However, one should also consider the type and quality of education they want to acquire as well. In addition, there was a negative relationship between training and unemployment and a positive relationship between schooling and citizen's current health. Regarding effects on the society, human capital help spread knowledge widely; hence, left a $10 \%$ to $25 \%$ impact on the annual growth of the US (Saxton, 2000).

Belonged to the same continent, the concern over human development of native citizens in Latin America had also been assessed. Looking at the data from 1994 to 2004, the typical return from additional education is $3 \%$ lower for indigenous people comparing to non-indigenous and this difference in grew at higher schooling levels. The gap leaded to the widening of distinction in earnings, especially for young workers and workers in nonagriculture area. Fortunately, the gap was shrinking and the gap had narrowed down by two-third since the 1970s (Patrinos \& Hall, 2005).

Hua (2005) takes into consideration the implication of three levels of education namely primary, secondary and university on the productivity growth - measured by total factor productivity (TFP) and its two components: technical progress (TP) and efficiency improvement (TE). The data used was from 29 provinces of China from 1993 to 2001. Having all of the necessary information, the economist calculates the Malmquist index and then applied the Generalized Moments Model for estimation. The relationship estimated were between TFP, TE, TP and the three levels of education with some additional economic variables such as export, foreign direct investment, capital labor. Their final finding was that only higher level of schooling was statistically big enough to support the links between our main variables. The impacts exerted from primary and secondary education were negative on technical efficiency change and not significant on technological progress. Therefore, university schooling level was an important for all efficiency change, technical change and the productivity growth. Is also was a major factor pooling highly educated workers to non-state sector in China, proving that Chinese government should continue their investment in this level of education (Hua, 2005).

\section{Methodology}

\subsection{Hypothesis}

The purpose of this research is to justify whether education has a positive influence on the economic growth of Vietnam in general. From the above reviews, it is expected that education and economic advances interact positively and significantly. Moreover, for a developing country like Vietnam, primary and secondary education will leave higher mark than university level. The model of Hua (2005) is the main reference of this paper.

\subsection{Variables Choices}

\subsubsection{Dependent Variable}

Determining the influences on such a subject like a country or an economy can be quite challenging, so smaller matter should be used for testing. According to Mankiw (2011), productivity plays an important role in every nation. Productivity here is defined as the quantity of output can be generated from each unit of input and is also the critical aspect of living standards. Consequently, productivity can be regarded as a representation of how well a country is doing; therefore, it is possible to utilize this figure to serve as the whole economy in calculation. In the mentioned paper, the author estimated productivity changes of the economy with Total Factor Productivity (TFP) index. TFP is the part of output that cannot be disclosed by the inputs used in production; as the result, it represent the efficiency of inputs utilization (Comin, 2010). Additionally, growth in long-run strategy depends on the growth in TFP and cross-country differences can be explained by TFP also. In conclusion, TFP is a fit estimation for productivity growth.

3.2.2 Independent Variables

Education is consider to be an important investment in every country for a better the long-run economic, even as 
crucial as physical capital (Mankiw, 2011). One method that education can influence the economy is by exerting human capital - a big motivation for technical progress, thus, productivity improvement (Hua, 2005). It also help facilitate countries to catch-up, spread technology widely as well as imitate newly available one (Geraint, 2006). This means that the lack of well-educated people can leads to failure in implementing technologies and inability to create new invention. Not only affecting the country by a whole, but schooling can also complement individuals' standard of living also. Moreover, by dedicating new ideas for the society, educated people can also aid the wellbeing of other bystanders (Mankiw, 2011). Nevertheless, due to the fact that each country is at a different level of development, the effect of education should not be considered under aggregated form (Akgüç, 2011). Moreover, a nation's ability to adopt, interpret and apply new technologies depends on different levels of education (Hua, 2005). As the result, to assess the actual power of schooling over the economy, there are three separated levels usually applied: primary, secondary and tertiary/higher education. Each of the mentioned levels' ratios are represented by diving the enrollment to the relevant population.

Among other available explanatory elements, openness to international trade is usually considered to be a conductive variables for financial development (Hua, 2005). This data is compute by dividing exports by its relative GDP. Barro agreed that this figure is a great determinant of economic growth and the fact that openness variable will produce positive impact on growth (Barro, 2002). However, Barro also noted that indications had been found proving that this effect would decrease as the country becomes richer.

Another factor of openness that could have notable influences on the economy is Foreign Direct Investment (FDI) (Hua, 2005). It is believed that investors can contribute their new technology and know-how to the host countries' production process and creates technology spillover - stimulating the growth of an economy (Hong, 2014). The FDI shall be considered as part of the gross fixed capital formation - GFCF.

One inevitable ingredient of all growth models that should be used is the human force, calculated by the labor force (from 15 years old to above) to population ratio. From the literature above, it can be interpreted that human contribute to the forward movement of a country by using their skills set - the human capital, to adopt and apply new technologies, consequently increase the productivity. Nevertheless, this also leads to the problem of inequality in human capital distribution and uneven schooling/training people get compared to each other. In addition, labor force also raise the management problem and the need to find an efficient utilization method (Hua, 2005). Thus, this can leads to mixed effects on the economic growth.

Next variable chosen by Hua (2005) was the exchange rate, and many researchers from the European Central Bank also agree. From their research, the relation between real exchange rate and growth had been confirmed. While weak exchange rate can compensate for the countries weaknesses and better the economy, over-/undervaluation can be quite harmful (Habib et al., 2017). One of the final findings was that the less developed the nation is, the bigger the effect of exchange rate is and as the country grow, the effect diminishes. For those reasons, the exchange rate is kept as a variable in this paper's model.

Government entities was listed as an important channel through which education can influence the economic condition (Hua, 2005). The main path that this type of firms can alter growth is by the redistribution of the labor force: in China, more and more workers are moving towards private enterprises for higher salary. Because of this fact and the excessive amount of less-educated employees, despite receiving enormous investment, the public sector's technical efficiency is constrained. However, in India there is somewhat a different stories: although the idea of state-owned organization being unproductive remains true, they still attracts lots of tertiary level graduates (Schündeln \& Playforth, 2014). In this South Asian country, the payments government officers receive was much higher than that of the private sector even though they are not productively assigned. From the above information, it can easily be seen that controversy among researchers in the use of this variables for developing countries still exist. For the case of Vietnam, there is a lack of theoretical and empirical works over this issue; hence, for the sake of this report solely, government entity data shall be neglected.

Finally, GDP per capita and the ratio of gaps between inventories and GDP changes were introduced as the 2 final options. According to Hua (2005), GDP per capita (lagged 1 year) is used to control the convergence effect pursuance with conventional growth theories (Hua, 2005). Regarding the gap ratio of inventories and GDP fluctuation, this number is included in the estimation to explain the impact of business cycle uncertainty on the effectiveness of inputs usage in the economy (Hua, 2005). Unfortunately, the data of Vietnam's inventory is not available on public sources; hence, this figure is dropped in this paper's model.

Finally, the 7 variables chosen are: the total factor productivity (TFP), primary, secondary and higher level of education, export ratio, foreign direct investment (FDI) ratio, capital-labor/labor force ratio and real exchange rate.

\subsection{First Model Construction}

Adjusting from the model used in Hua (2005) for the changes made in the process of choosing variables as described in the former section, the variables relating inventory gap, public corporation and GDP per capita will be dropped. The model will be used in this research composed of 7 variables: 
Where:

$$
\mathrm{TFP}=\mathrm{c}_{1} \mathrm{EDUP}+\mathrm{c}_{2} \mathrm{EDUS}+\mathrm{c}_{3} \mathrm{EDUU}+\mathrm{c}_{4} \mathrm{EX}+\mathrm{c}_{5} \mathrm{FDI}+\mathrm{c}_{6} \mathrm{KL}+\mathrm{c}_{7} \mathrm{ER}+\mathrm{e}_{\mathrm{i}}
$$

TFP denotes estimated value of TFP;

EDUP denotes primary level of education;

EDUS denotes secondary level of education;

EDUU denotes tertiary/higher level of education;
FDI denotes FDI ratio;

EX denotes export ratio;

KL denotes capital-labor ratio;

ER denotes exchange rate ratio;

\subsection{Second Model Construction}

When assessing the heath of an economy, besides from its productivity, it is also possible to look at the income from all members - which is measured by the economy's GDP ${ }^{1}$ (Mankiw, 2011).

GDP serves as the total market value of domestically produced goods and services in a specific time period. This number gives the overall assessment of all goods and services traded legally in markets, and omits all illegal transactions or goods not used to trade in the market. Also, the mentioned goods and services must be the final products ready to be sold and they must the freshly made, transactions involving used goods will not be included in GDP calculation.

A part from measuring the total goods and services produced, GDP can also be used as a representation of the total income and expenditure of all citizens in one country. Moreover, since every business dealings have two parties: the buyer and the seller, every expenditure of buyers will become payment for sellers. For that reasons, the expenses and income of a nation are identical.

Despite of the fact that GDP neglect the environment condition, leisure activities for people and other nonmarket transaction, it remains a remarkable measurement and the first step to develop a full understanding of one economy. Moreover, GDP also reflect the output of the whole nation, it is safe to state that GDP somewhat symbolized the productivity of that country. Hence, it is worthwhile to use GDP related data in this paper. To measure account for economic growth using GDP data, GDP growth ratio can be adopted as the dependent variable. Assembling the new model, simply replace TFP by GDP growth:

$$
\text { GDPG }=c_{1} \text { EDUP }+c_{2} \text { EDUS }+c_{3} \text { EDUU }+c_{4} E X+c_{5} \text { FDI }+c_{6} K L+c_{7} E R+e_{i}
$$

Where GDPG denotes GDP growth rate.

\subsection{Estimating the first model TFP}

Among multiple methods could be maneuvered to compute productivity index such as partial productivity or putting TFP as the portion of production and weighting sum of production factors (Hua, 2005). As the consequence, DEA method is used to calculate TFP index.

DEA is a quite popular and basic method, especially in economic fields, for estimating the effectiveness of technology and assessing the changes of productivity. It uses a linear mathematical model and distance functions for computation (Nguyen et al., 2013). This method was the invention of Farell when he came up with the idea of applying the production possibility frontier curve as a criterion for comparing relative effectiveness among companies in the same industry. The benefit of DEA is its precision, ability to account for several input/output factors, and the fact that it does not require the production function form to be known. Thus, it is widely utilized in research papers.

Using DEA, TFP can be measure through the calculation of Malmquist index (Coelli, 1996). Malmquist index was first introduce by the late professor Sten Malmquist, his intention with this index was to construct an quantity index with the input distance functions (Althin, 2001). At the moment there are 2 trends of exploiting this ratio: adjacent Malmquist and base period Malmquist; however, the distinction between these 2 methods is not significant (Althin, 2001).

Thanks to the advancement of technology, all of the related calculation to DEA and Malmquist index can be done using a DEAP computer program version 2.1 (as recommended by Hua (2005)). This program is written by Tim Coelli and is available online.

\subsection{Estimating the second model}

Among the mentioned literature, both Hua (2005)'s and Schündeln (2014)'s utilized Generalized Moments Model or the Generalized Method of Moments (GMM). This method since 1982 had been a major procedure for approximately produce economic/financial models (Chaussé, 2010). The biggest reasons for the popularity of it is because it can save user from using unwanted hypothesis (Chaussé, 2010). For example, no assumption is needed about the distribution of the sample nor covariance matrix. For those reasons, to avoid making further assumption about the data, GMM method is also applied.

\footnotetext{
${ }^{1}$ Gross Domestic Product
} 


\subsection{Data overview}

In order to provide reliable conclusion from the above model, collecting data is one of the most important step. Firstly, the time period of the data set needs to be determined. Based on the available in formation and the accuracy as well as up-to-date requirement, the annual data of the period from 2000 to 2015 and the currency US Dollar are used for this paper

Afterwards, educational enrollment figures were gathered initially. These numbers can be easily found on the website of Ministry of Education and Training Vietnam, under the tab Statistics. The Ministry has produced a number of statistical reports over the education system condition over the period of 1999 to 2012 . The data for the 3 years 2013, 2014 and 2015 were still under construction when this research was written, but they can be abstracted from General Statistic Office of Vietnam (GSO) website under separated statistical research on Vietnam overall educational system. As decided in the "Variable choices" section, the data on total population of the 20002015 period will also be required. They can also be found of the GSO; moreover, the World Bank did collect statistics over this issue too. Since the collected numbers do not varies significantly from each other, World Bank version of Vietnamese population is chosen for its international nature. Having these fundamental data, the enrollment ratio can be calculated. There were a major downward trend in primary (from grade 1 to 5) and secondary (from grade 6 to 12) education: they started at around 12.5\% and 10.5\% respectively but both finished at $8 \%$ in 2015 . Though enjoyed light increase, but the tertiary schooling participation level only stood at $2.3 \%$ in 2015. The means of primary and secondary education are around $10 \%$ while this number of higher education is only $1.9 \%$

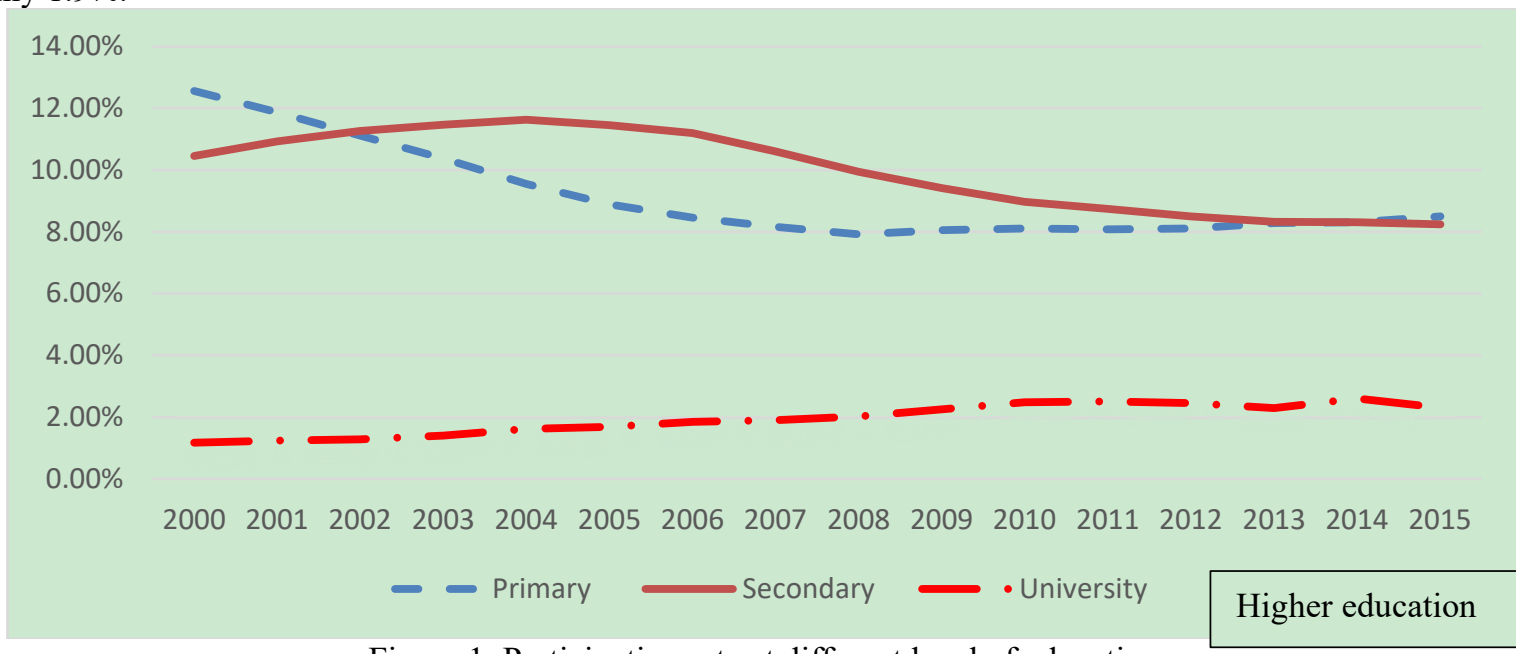

Figure 1. Participation rate at different level of education

Next, the exporting capacity should be collected, which can also be found in GSO website. To compute the export ratio, GDP data must be obtained. Again, both GSO and World Bank have issued reports on this matter, but World Bank figures are preferred. After retrieving the ratio, it can be seen that though the data took a huge plunge in 2009, the overall trend was upward and in 2015, exporting accounted for over 80\% of Vietnam's GDP.

Thirdly, the numerical value of FDI ratio should be determined. To calculate this number, FDI and Gross Fixed Capital Formation (GFCF) should be collected. While GFCF can be discovered in World Bank website, the GSO data over FDI to Vietnam was chosen because they provided the actual performed FDI. The FDI ratio over GFCF suffered from great fluctuation during the first 10 years, but the last 7 years was quite stable. The ending number lie quite close to the beginning one with slight reduction - around $30 \%$.

After that, capital-labor or the labor force is put under consideration. Mankiw (2011) defined the labor force is the total number of available workers, comprising both ones that have jobs and people that do not. World Bank's definition of labor force is quite similar, so its labor summarization was put to practice. The graph can be drawn from Vietnam labor market climbed gradually and in 2015 Vietnam had over 55 million people capable of working. 


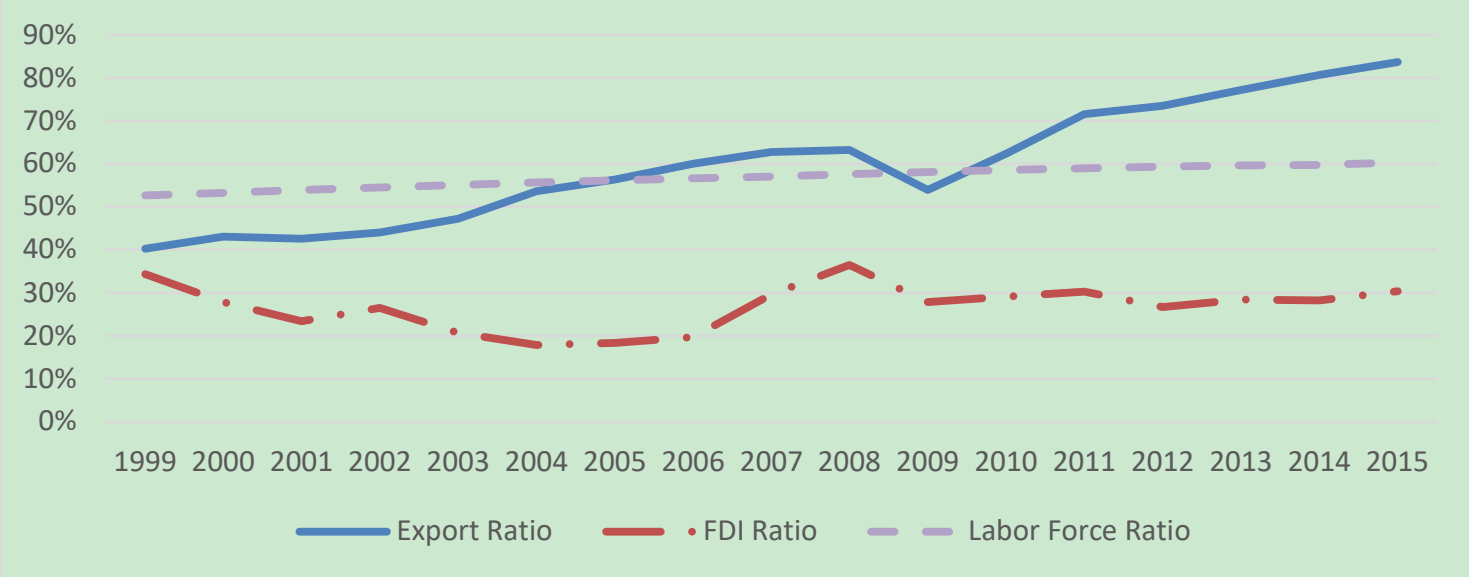

Figure 2. Vietnam's export ratio, FDI ratio and labor force ratio graph

Vietnamese Dong (VND) exchange rate was the last ingredients needed to finalize the model. In order to look into the fluctuation of Vietnamese currency's value, VND should be the base currency of the requested exchange rate. Moreover, because of its popularity, United State Dollar (USD) was used as the counter currency for comparison. This data shared the same source and trend with the labor force, these number rose steadily which means the value of VND decreased; nonetheless, the period 2011-2012 witnessed a stiffer change.

Besides the original variables' data, to account for the additional model, the data of GDP growth of Vietnam also need to be collected. World Bank still a reliable source where this figure can be found. From 2000 to 2003, the growth rate of Vietnam fell slightly from 7\% to around 6\%, but it shot up and reached around $7.5 \%$ in 2005 . This number remained stable for only 1 year then started to decreased and touched the low point of $5.4 \%$ in 2009 . There was a small rise in 2011 but then it dropped back to only $5.2 \%$. Fortunately, the growth rate of GDP accelerated in the last 3 years of the period and ended at approximately $6.7 \%$ in 2015 .

Table 1. GDP Growth Rate and VND/USD Exchange Rate

\begin{tabular}{|l|l|l|l|l|l|l|l|l|}
\hline Year & 2000 & 2001 & 2002 & 2003 & 2004 & 2005 & 2006 & 2007 \\
\hline GDP Growth & $6.79 \%$ & $6.19 \%$ & $6.32 \%$ & $6.90 \%$ & $7.54 \%$ & $7.55 \%$ & $6.98 \%$ & $7.13 \%$ \\
\hline Exchange Rate & 14,168 & 14,725 & 15,280 & 15,510 & 15,746 & 15,859 & 15,994 & 16,105 \\
\hline Year & 2008 & 2009 & 2010 & 2011 & 2012 & 2013 & 2014 & 2015 \\
\hline GDP Growth & $5.66 \%$ & $5.40 \%$ & $6.42 \%$ & $6.24 \%$ & $5.25 \%$ & $5.42 \%$ & $5.98 \%$ & $6.68 \%$ \\
\hline Exchange Rate & 16,302 & 17,065 & 18,613 & 20,510 & 20,828 & 20,933 & 21,148 & 21,698 \\
\hline
\end{tabular}

\section{Econometric model estimation}

\subsection{DEAP test}

DEAP software is used to calculate the TFP changes. Since it only compute the fluctuation throughout the selected period, to obtain results for 16 years from 2000 to 2015, the data from 1999 is required. Moreover, DEAP work best with more than just one input and output, a number of them are selected. For outputs, I chose GDP and openness measured by the export ratio because they are most likely be affected by the country's productivity. For any economy to produce outputs, the two most important inputs are physical capital and the workers themselves. Physical capital is defined as the tools and facilities can be handle to produce goods and services (Mankiw, 2011). It is a critical component because not only it is crucial to produce all goods and services but also to reproduce itself. The physical capital can be evaluate by capital stock of a society, which is the outcome of GFCF and depreciation rate (Hua, 2005). Regrettably, annual deprecation rate of Vietnam is not published, but I was able to find the data of "Overall capital for society's development" on GSO website. This number can be considered as somewhat a replacement for capital stock in this research because of their similarity. As for the labor force, as common knowledge, is the one who manipulate the capital to process them into final products, can be symbolize by the data of the labor force. Then, since DEAP is a DOS program, all data files must be saved as text files and then process using a line of command in the instruction file (Coelli, 1996).

With those 4 factors, now we can use DEAP version 2.1 to calculate TFP changes for Vietnam from 2000 to 2015. The results showed that our TFP figure varied greatly throughout the years with an annual average of $1.11 \%$. The number started at $3.2 \%$ and then decreased gradually until it touched $0.36 \%$ for the first 3 years. There was a small increase in 2004 when the number reached $4.49 \%$ but in 2013 the line rocketed to the point of almost $19.5 \%$. The lowest point that TFP fell to was 0.123 in 2011.

Since TFP is explanation for efficiency in resources usage, this showed that Vietnam is not maximizing the profit that our input could bring. Though there were some period of time with significantly high return, but the overall trends still alert of the poor utilization of resources. Below is reflection of part of Vietnam's data with some 
other countries available on Penn World Table - (Feenstra, Inklaar, \& Timmer, 2015).

Table 2. TFP index of some countries from Penn World Table and Vietnam's result

\begin{tabular}{|l|l|l|l|l|l|l|}
\hline Year & Thailand & Indonesia & Turkey & Philippines & Malaysia & Vietnam (calculated) \\
\hline 2006 & 0.445 & 0.352 & 1.039 & 0.396 & 0.605 & 0.899 \\
\hline 2007 & 0.451 & 0.343 & 0.982 & 0.407 & 0.633 & 1.307 \\
\hline 2008 & 0.450 & 0.364 & 1.019 & 0.403 & 0.669 & 2.402 \\
\hline 2009 & 0.424 & 0.356 & 1.028 & 0.412 & 0.613 & 2.07 \\
\hline 2010 & 0.451 & 0.357 & 1.006 & 0.426 & 0.598 & 0.123 \\
\hline 2011 & 0.448 & 0.373 & 1.032 & 0.425 & 0.629 & 1.892 \\
\hline 2012 & 0.471 & 0.378 & 0.994 & 0.434 & 0.631 & 1.943 \\
\hline 2013 & 0.445 & 0.377 & 0.982 & 0.458 & 0.637 & 0.414 \\
\hline 2014 & 0.429 & 0.387 & 0.940 & 0.461 & 0.616 & 0.218 \\
\hline
\end{tabular}

As can be observed from the above table, the outcome from calculation of Vietnam's TFP stood out from some other available data. For that reasons, although followed closely steps from the main reference, Vietnam's TFP is not accurately calculated. Nonetheless, for the sake of following Hua (2005)'s theory, TFP and equation (2) are still put under consideration.

\subsection{Quantitative estimation}

4.2.1 Estimation of the first model

To comply with the original work by Hua (2005), equation number (3) is estimated. Using all the information gathered, the final result was:

$$
\begin{gathered}
\widehat{\text { TFP }}=-1088.672 * \text { EDUP }-855.4758 * \text { EDUS }-1814.096 * \text { EDUU }-22.198 \\
* \mathrm{EX}-107.3975 * \text { FDI }-931.5905 * \mathrm{KL}+0.00399 * \mathrm{ER}+706.5341 \\
\mathrm{t}_{\mathrm{EDUP}}=-1.818 \mathrm{t}_{\mathrm{EDUS}}=-1.431 \quad \mathrm{t}_{\mathrm{EDUU}}=-1.163 \mathrm{t}_{\mathrm{EX}}=-1.532 \\
\mathrm{t}_{\mathrm{FDI}}=-0.799 \quad \mathrm{t}_{\mathrm{KL}}=-2.015 \quad \mathrm{t}_{\mathrm{ER}}=1.827 \quad \mathrm{R}^{2}=0.342 \quad \text { Adjusted } \mathrm{R}^{2}=-0.2345
\end{gathered}
$$

The above estimation product cannot considered to be efficient as most of the variable coefficient turned out to be much smaller than zero. This means that they delivered great negative effects on GDP growth. This is unprecedented and cannot be explained by any previous work; therefore, the model is questionable. Equation (3)'s $\mathrm{R}^{2}$ and adjusted $\mathrm{R}^{21}$ are 0.3415 and -0.2345 respectively, which give evidences that it does not have the ability to explain the independent variables' impact on GDP growth. By using this data with the null hypothesis of variables are not statistically greater than 0 , the explanatory power of the variables can be tested. Except for the error term and labor ratio, the other 6 variables' $p$ values are all greater than 0.05 , which means the lowest significance level to reject the null hypothesis exceed 0.05 - the regular mark. As the result, there is not enough evidence for them to be larger than 0 and have effect on the variation of estimated TFP value. Combining all of the above factors, equation number (3) is proven to be unable to explain the changes of TFP; hence, the changes of the economy.

4.2.2 Estimation of the second model

As for equation (3), after processing the data using Eviews 9, the first collected equation was capable of explaining the effect of education levels on GDP growth. The R2 as well as adjusted R2 are much better than equation (4), around 0.74 and 0.51 respectively. In addition, 6 out of 8 variables' coefficients are positive; however, most of their $\mathrm{p}$ values are still quite high. Therefore, ways to better the model estimation is needed.

Looking at the probability of the 8 instruments (including 7 variables and 1 residual) in the equation, FDI ratio had the highest of them all. As the result, a test for dropping FDI ratio was performed. Luckily, Eviews also provided redundant variable test using $\mathrm{J}$ statistic for GMM estimation. After using this equation, the probability to drop of FDI ratio was 0.3020 - much higher than the usual 0.05 or 0.1 significance level for rejection. Hence, there is proof that FDI ratio is not relevant to equation (3). This might be caused by the fact that one of FDI main effect in on export section of Vietnamese economy ( $\left.\mathrm{MPI}^{2}, 2013\right)$, consequently it did not impact the whole economy directly but through the channel of exportation. Additionally, one big drawbacks of Vietnam economy is that there had not been efficient method to attract and manage the foreign direct investment into our country. For example, the main flow of money was still on assembling chains with small added value; although there had been multiple massive real estate projects, the commencement and completion of them were very time-consuming. Another drawbacks was the limitation disbursement of technology from the investor, only $5 \%$ to $6 \%$ of them established high technology while $14 \%$ still use outdated techniques/machines. To sum up, withdrawing FDI ratio from the estimation was supported by both numerical and theoretical reasons.

Afterwards, the adjusted R2 was boosted, but only by around 3\%. To increase the dependability of the model,

\footnotetext{
${ }^{1}$ The coefficient of determination, it shall be explained in the latter part

${ }^{2}$ Ministry of Planning and Investment, 2013
} 
we can look at the nature of our independent variables. Among all, the labor force and exchange rate had the potential to be distinguished from others. Both of their fluctuations not only influence the current period economy condition but also the latter one. For instance, the increase in labor force this year may also affect the capacity of the next year since the additional workers will continuously produce output. Likewise for exchange rate, its fluctuation can affect the value of long-term transaction, hence, affect the economy in more than just one period. To take these factors into consideration, labor force ratio and exchange rate are adjusted to be lagged one period. Thanks to the adjustment, the R2 and adjusted R2 were raised to 0.85 and 0.74 .

Finally, the estimated equation (4) took the form:

$$
\begin{gathered}
\widehat{\mathrm{GDPG}}=1.222 * \mathrm{EDUP}+1.691 * \mathrm{EDUS}+1.519 * \mathrm{EDUU}+0.076 * \mathrm{EX}+1.234 * \mathrm{KL}_{\mathrm{t}-1}-5.6 * 10^{-06} * \\
\quad \mathrm{ER}_{\mathrm{t}-1}-0.897 \quad(4) \\
\mathrm{t}_{\mathrm{EDUP}}=3.398 \quad \mathrm{t}_{\mathrm{EDUS}}=5.126 \quad \mathrm{t}_{\mathrm{EDUU}}=1.079 \quad \mathrm{t}_{\mathrm{EX}}=4.37 \\
\mathrm{t}_{\mathrm{KL}-1}=3.689 \quad \mathrm{t}_{\mathrm{ER}-1}=-4.204 \mathrm{R}^{2}=0.853, \text { Adjusted } \mathrm{R}^{2}=0.74
\end{gathered}
$$

Where GDPG denotes estimated value of GDP growth; EDUP denotes primary level of education; EDUS denotes secondary level of education; EDUU denotes tertiary/higher level of education; EX denotes export ratio; $\mathrm{KL}_{\mathrm{t}-1}$ and $\mathrm{ER}_{\mathrm{t}-1}$ denote capital-labor ratio and exchange rate ratio lagging one year.

From equation number (4), we can conclude that 3 levels of education namely primary, secondary and university exert direct and positive effects over the growth of GDP. Holding other variables constant, with each percentage of increase in primary education will better the GDP growth by $1.222 \%$. These numbers of secondary and university levels are $1.691 \%$ and $1.519 \%$ respectively. Export and labor force lagging 1 year generated the same effect as primary and secondary schooling. The $1 \%$ escalation of them will individually better the economic growth by $0.07 \%$ and $1.23 \%$ on average respectively. With other variables being unchanged, exchange rate provokes negative movements for GDP growth with the coefficient is about $-5.6 \times 10^{-06}$.

After carrying out the t-test, the outcome is that only two lower schooling section contributed directly and positively to GDP growth. This complied with a few findings from a few works such as Mingat and Tan (1996), Montenegro and Patrinos (2013). Since 2008, Vietnam had been listed as a middle-income country (Ohno, 2009), and for middle-income country, investment in primary and secondary bring most profit (Mingat \& Tan, 1996). Moreover, secondary is demonstrated to be most beneficial for this type of country and the expansion of higher education is not efficient (Mingat \& Tan, 1996). Montenegro and Patrinos (2013) also agreed with these statements by giving evidence that for middle income countries, the average years of schooling around 9 to 11 years were the most effective for the growth of the economy (Patrinos \& Montenegro, 2013). The main explanation for these empirical findings (including the one in this paper) is because of the lower levels of education's nature. Vietnam is still a developing country, so the need of catching up with the rest of the world is more favorable to being the leader. Primary and secondary training system have the ability to satisfy our demand: they trigger the adoption and imitation process of new technologies while higher level of education produce materials for innovation (Akgüç, 2011).

With the same method of testing, export ratio, labor force ratio and exchange rate are also statistically significant with t-statistic value of $4.37,3.689$ and -4.205 respectively.

\subsection{Robustness}

To check the accuracy of the estimation, the overidentification problem using GMM I want to mention is the utilization of GMM as the main method. There is no clear instruction over how to employ it, as the consequent, I was not able to maximize its potential. Moreover, since this is the first time introduced to this method, the some procedure for error detection such as multicollinearity, heteroscedasticity detections, were not performed. Moreover, there was no guide for performing the test for model choice; hence, the functional form test is carried out to make the decision. The functional form test procedure for Ordinary Least Squared method was compiled. Additionally, the original work mentioned the data of TFP, but due to the lack of DEAP's instruction, TFP could not be produced.

\section{Conclusion}

This paper aims to test the relationship between education and the economic growth in Vietnam. After analyzing some of the paper written by famous economist, financial advances had been proved to be under influence of schooling, specifically three levels of education namely primary, secondary and higher education level. With these findings, the hypothesis of this research is determined as Vietnam's economic growth will be directly linked to education. To justify for this statement, a model has been constructed and tested based on the instruction from Hua (2005)'s work. With GMM as the main estimator method, the estimation of the proposed model was achieved. Final conclusion was proven to be supportive to the hypothesis made: Primary and secondary education level impacts the growth of GDP positively, but the higher education do not have any effect. As GDP growth can be considered a parameter for the economic growth of a country, primary and secondary schooling level consequently leave great effect on economic growth of Vietnam. 
From former literatures, primary and secondary education levels have the capability to supply corresponding skills set to developing countries. Thus, investment in lower levels of education is best for Vietnam. The government should maintain and expand the current generalization plan for primary and secondary schooling to boost the prosperity of the society. Nonetheless, even though we are in the early stage of development, university schooling importance should not be forgotten. University graduates are the main components for the success of catching up, spreading and imitating/applying advanced technologies from developed nations (Hua, 2005); as the result, university education is essential for long-term evolution.

This paper gathered multiple literatures as foundation, therefore, it has the ability to provide knowledge and theories for further studies. Also thanks to the fact that the model was established with a decent amount of theoretical support, its results are reliable to be used in future research.

\section{References}

Akgüç, M. (2011). The effects of different stages of education on income across countries: paper, Toulouse School of Economics (TSE).

Althin, R. (2001). Measurement of productivity changes: two Malmquist index approaches. Journal of Productivity Analysis, 16(2), 107-128.

Barro, R. (2002). Education as a Determinant of Economic Growth. In E. P. Lazear (Ed.), Education in the TwentyFirst Century: Hoover Institution Press.

Chaussé, P. (2010). Computing generalized method of moments and generalized empirical likelihood with R. Journal of Statistical Software, 34(11), 1-35.

Coelli, T. (1996). A guide to DEAP version 2.1: a data envelopment analysis (computer) program. Centre for Efficiency and Productivity Analysis, University of New England, Australia.

Comin, D. (2010). Total factor productivity Economic Growth Springer, (pp. 260-263).

Development, G. B. D. f. I. (2008). Growth - Building Jobs and Prosperity in Developing Countries: Department of International Development.

Feenstra, R. C., Inklaar, R., \& Timmer, M. P. (2015). The next generation of the Penn World Table. The American Economic Review, 105(10), 3150-3182.

Geraint, J. (2006). Education and economic growth. For presentation as the twelfth lecture in the Eric John Hanson Memorial Lecture Series at the Department of Economics, University of Alberta, Edmonton.

Habib, M. M., Mileva, E., \& Stracca, L. (2017). The real exchange rate and economic growth: revisiting the case using external instruments. Journal of International Money and Finance.

Hong, L. (2014). Does and how does FDI promote the economic growth? Evidence from dynamic panel data of prefecture city in China. IERI Procedia, 6, 57-62.

Hua, P. (2005). Impacts of Different Levels of Education on TFP Growth: Evidence from China China Economic Quarterly (Vol. 5, pp. 147-166): Centre d'Études et de Recherches sur le Développement International.

Korotayev, A., Goldstone, J. A., \& Zinkina, J. (2015). Phases of global demographic transition correlate with phases of the Great Divergence and Great Convergence. Technological Forecasting and Social Change, 95, 163-169. doi: https://doi.org/10.1016/j.techfore.2015.01.017

Mankiw, N. G. (2011). Principles of Economics, 5th edition: South-Western Cengage Learning.

Mingat, A., \& Tan, J.-P. (1996). The full social returns to education : estimates based on countries' economic growth performance. $1(1), 30$.

MOET. (2014). Education for All 2015 National Review Report: Viet Nam. Hanoi: Ministry Of Education and Training.

Moretti, E. (2004a). Estimating the social return to higher education: evidence from longitudinal and repeated cross-sectional data. Journal of Econometrics, 121(1-2), 175-212.

Moretti, E. (2004b). Workers' education, spillovers, and productivity: evidence from plant-level production functions. The American Economic Review, 94(3), 656-690.

Moretti, E., \& Lochner, L. (2004). The effect of education on crime: Evidence from prison inmates, arrests, and self-reports. The American Economic Review, 94(1), 155-189.

Ngo, T. H. (2015). Moi quan he giua tang truong kinh te va ngan sach giao duc tai Viet Nam giai doan 2000 - 2012. Tap chi Phat Trien và Hoi Nhap, 24 (34) (September - October 2015), 4.

Nguyen, D. T. T., Vuong, D. Đ., Le, H. T., Nguyen, C. D., \& Hoang, H. Y. T. (2013). Phan tich hieu qua hoat dong cua cac ngan hang thuong mai o Viet Nam giai doan 2008 - 2011 (F. o. E. Science, Trans.). Hanoi National Economic University.

Fontenele, R. E. S., Sena, A. M. C. (2015). The New Endogenous Growth Theory: An Investigation on Growth Policy for Developing Countries. University Federal of Cearas.

OCED. (2013). What are the benefits of education? Education indicators in focus (pp. 1): OCED.

Ohno, K. (2009). Avoiding the middle-income trap: renovating industrial policy formulation in Vietnam. ASEAN Economic Bulletin, 26(1), 25-43. 
Patrinos, H. A., \& Hall, G. (2005). Indigenous peoples, poverty and human development in Latin America: Springer.

Patrinos, H. A., \& Montenegro, C. E. (2013). Returns to Schooling around the World. Background Paper for the World Development Report.

Patrinos, H. A., \& Montenegro, C. E. (2014). Comparable estimates of returns to schooling around the world. Policy Research paper Series.

Sardadvar, S. (2011). Neoclassical Growth Theory and Standard Models Economic Growth in the Regions of Europe: Theory and Empirical Evidence from a Spatial Growth Model (pp. 9-22). Heidelberg: Physica-Verlag HD.

Saxton, J. (2000). Investment in education: Private and public returns. Paper presented at the Washington DC: Joint Economic Committee, United States Congress.

Schündeln, M., \& Playforth, J. (2014). Private versus social returns to human capital: Education and economic growth in India. European Economic Review, 66, 266-283.

Sena, A. M., \& Fontenele, R. E. S. (2000). The New Endogenous Growth Theory: An Investigation on Growth Policy for Developing Countries.

Ucak, A. (2015). Adam Smith: The Inspirer of Modern Growth Theories. Procedia-Social and Behavioral Sciences, $195,663-672$. 